1 Multiomic Analysis Elucidates the Reasons Underlying the Differential Metabolite

2 Accumulation in Citrus Mature Leaves and Fruit Juice Sacs

3

4 Authors:

5 Ling-Xia Guo ${ }^{1,2 \#}$, Syed Bilal Hussain ${ }^{1,2 \#}$, Alisdair R. Fernie ${ }^{3}$, Yong-Zhong Liu ${ }^{1,2 *}$, Min Yan ${ }^{1,2}$,

6 Huan Chen ${ }^{1,2}$, Shariq Mahmood Alam ${ }^{1,2}$

7

8 Addresses:

$9 \quad{ }^{1}$ Key Laboratory of Horticultural Plant Biology (Ministry of Education), Huazhong 10 Agricultural University, Wuhan 430070, P.R. China

$11{ }^{2}$ College of Horticulture \& Forestry Sciences, Huazhong Agricultural University, Wuhan 12 430070, P.R. China

$13{ }^{3}$ Max-Planck-Institute of Molecular Plant Physiology, Am Mühlenberg 1, 14476

14 Potsdam-Golm, Germany

15

16 \# Equal contribution.

17

18 *Corresponding author: Yong-Zhong Liu

19

Tel: +86-27-87281897; Fax: +86-2787282010

20 E-mail address: liuyongzhong@mail.hzau.edu.cn; orcid.org/0000-0002-2279-3123 


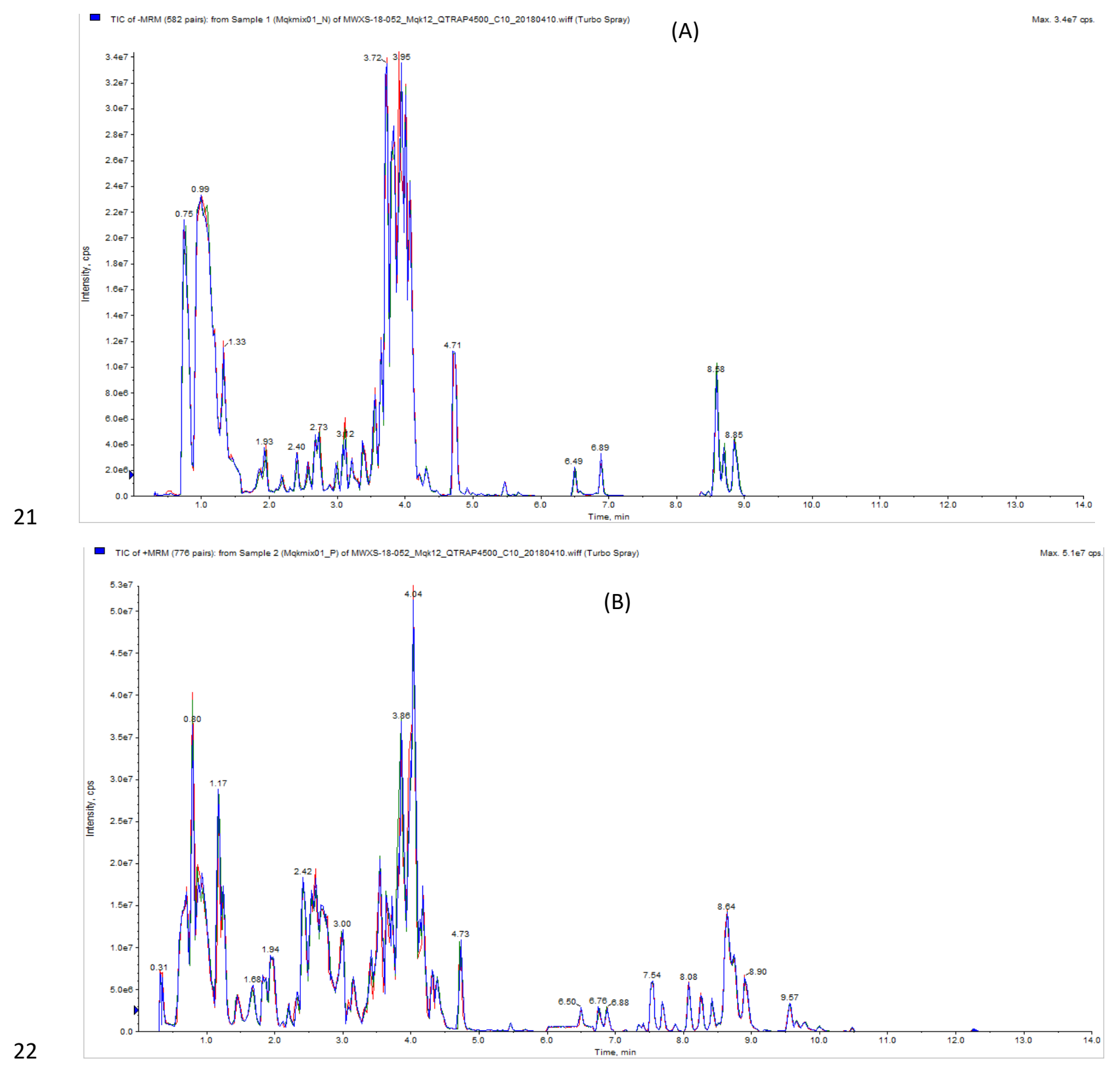

23 Fig. s1 Overlap of QC-MS-TIC (total ions current) with negative (A) and positive (B) modes. 

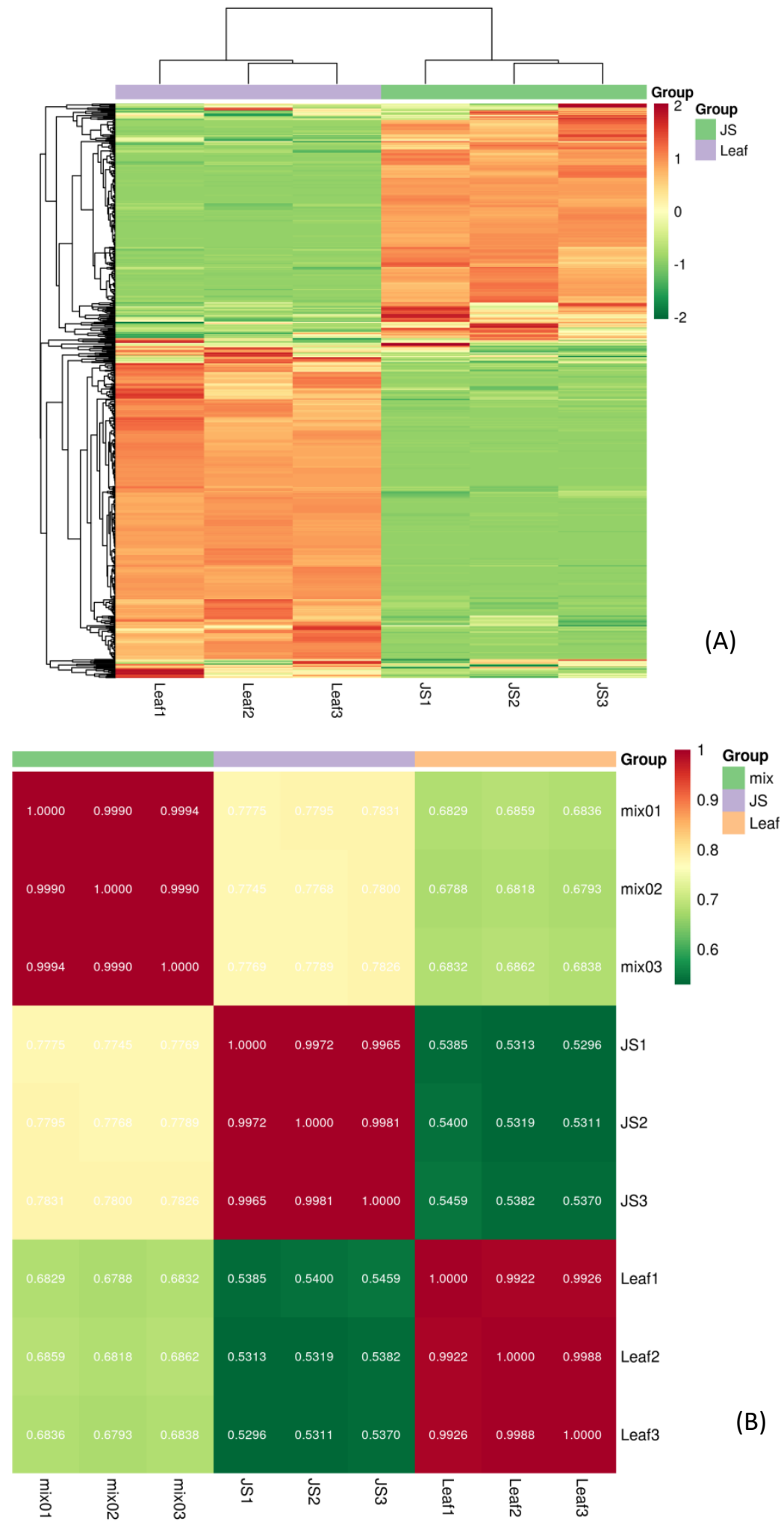

27 Fig. s2 Analysis of the hierarchical cluster (A) and Pearson's correlation coefficient (B) of 28 ML and JS samples. 
(A)
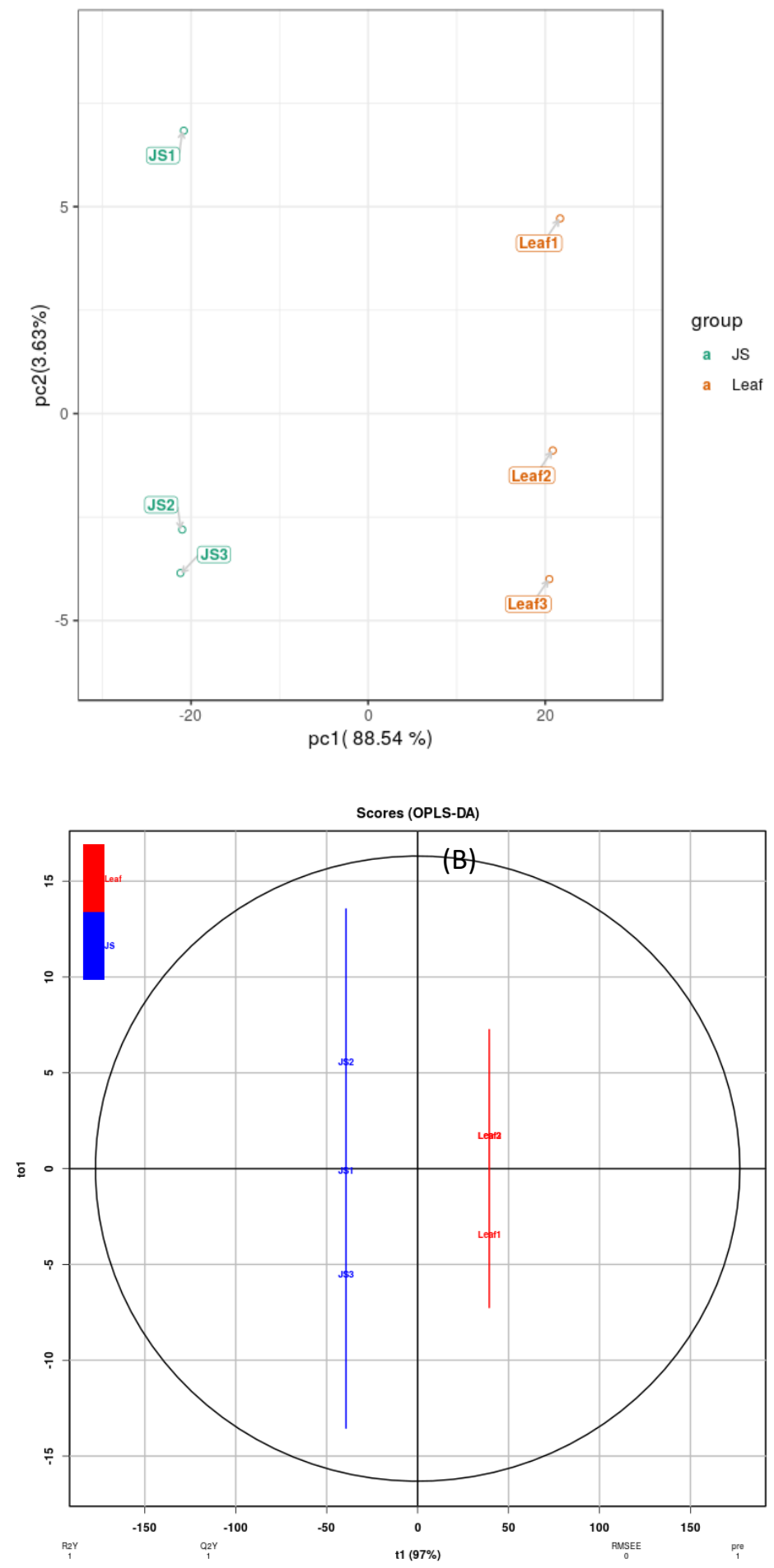


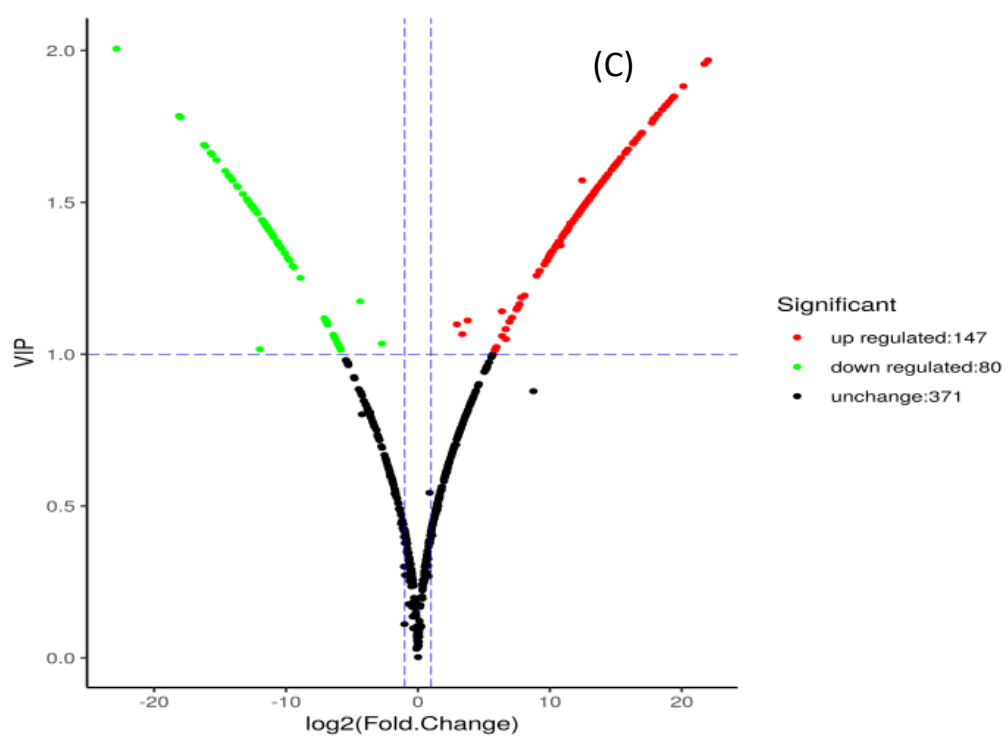

32 Fig. s3 PCA (A), OPLS-DA (B) analyses, and Volcano Plot (C). 
(A)

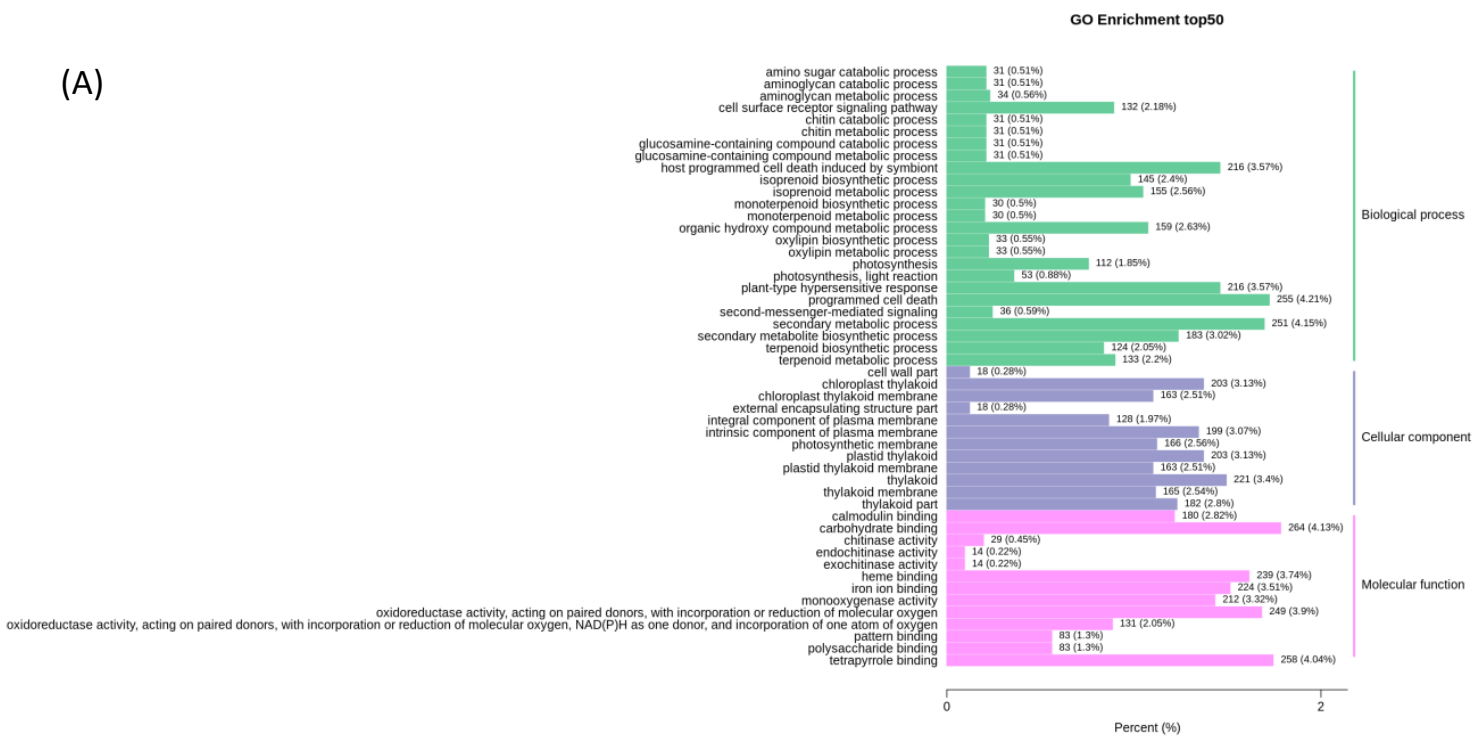

(B)

\section{Statistics of KEGG Enrichment}

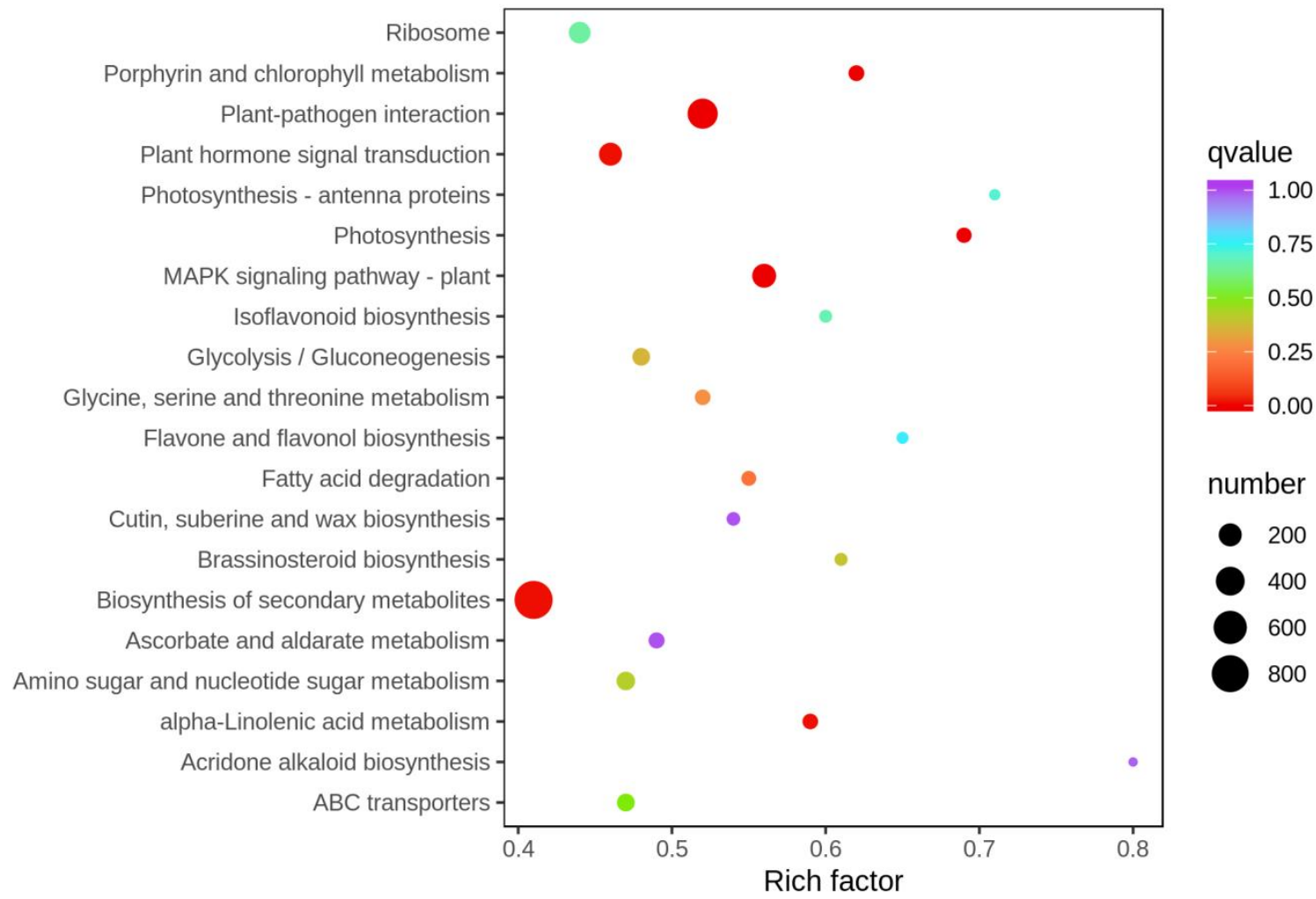

36 Fig. s4 Gene ontology (GO) enrichment Top 50 (A) and statistics of KEGG enrichment (B)

37 for differentially expressed metabolites. 
Table s1 Primers for qRT-PCR

\begin{tabular}{|c|c|c|c|}
\hline $\begin{array}{l}\text { Gene } \\
\text { Name }\end{array}$ & Gene ID & Forward Primers (5'-3') & Reverse Primers (3'-5') \\
\hline \multirow[t]{2}{*}{ CsPH8 } & Cs1g16150 & CCGTGAAGGAATTGATTTGG & CCATGACAATGGATTCCACA \\
\hline & & GACTGAGGCAAGCCAAAGAAG & AGCCCCAGCATTAAGATGATG \\
\hline CsVHA-G & Cs6g11650 & A & A \\
\hline CsVHA-a2 & Cs8g08330 & AAAAGTGTCTTGTGGGTGAGGG & GCGAAAATAGGTAGGCGGAG \\
\hline CsVHA-cl & Cs8g07570 & CGCCCTTGTCTTCTCCTGTAT & GACTTGGCCTTGGGGTTAATC \\
\hline CsVHA-c3 & Cs1g25080 & GTATGGGACGGCGAAGAGTG & CAAGCGAGACCCGAAGACAA \\
\hline CsVHA-c, & Cs4g20460 & TCACCATATACCTTCTCCGCC & ATAATTGCAACAATGACCCCA \\
\hline CitACL $\beta 1$ & $\mathrm{Cs} 9 \mathrm{~g} 02230$ & ATCCAACGGCTGATGTTTTC & ACCGAGCGTATGCAATCAAT \\
\hline $\mathrm{CsCHI}$ & Cs7g29780 & AACAAAGTCGCATTTCCTCGGC & GCACGGCGTTCTCCTCCAAGTA \\
\hline Actin & $\begin{array}{l}\text { XM_00646450 } \\
3\end{array}$ & CCGACCGTATGAGCAAGGAAA & TTCCTGTGGACAATGGATGGA \\
\hline
\end{tabular}


Table s3 Sequencing and assembly statistics for the six transcriptome data

\begin{tabular}{ccccccc}
\hline Sample & $\begin{array}{c}\text { Total Clean } \\
\text { Reads (bp) }\end{array}$ & $\begin{array}{c}\text { Error rate } \\
\mathbf{( \% )}\end{array}$ & $\begin{array}{c}\text { Q20 } \\
\mathbf{( \% )}\end{array}$ & $\begin{array}{c}\text { Q30 } \\
\mathbf{( \% )}\end{array}$ & $\begin{array}{c}\text { GC Content } \\
(\mathbf{\% )}\end{array}$ & Reads mapped \\
\hline JS1 & 60727158 & 0.01 & 97.84 & 94.41 & 44.71 & $53043395(87.35 \%)$ \\
JS2 & 53414500 & 0.01 & 97.79 & 94.31 & 44.71 & $46634650(87.31 \%)$ \\
JS3 & 46241298 & 0.01 & 97.98 & 94.69 & 44.61 & $40593110(87.79 \%)$ \\
Leaf1 & 59535254 & 0.01 & 97.59 & 93.87 & 43.79 & $52052133(87.43 \%)$ \\
Leaf2 & 63755760 & 0.01 & 98.28 & 95.57 & 43.71 & $55871901(87.63 \%)$ \\
Leaf3 & 60553312 & 0.01 & 97.8 & 94.32 & 43.71 & $53370663(88.14 \%)$ \\
\hline
\end{tabular}

